
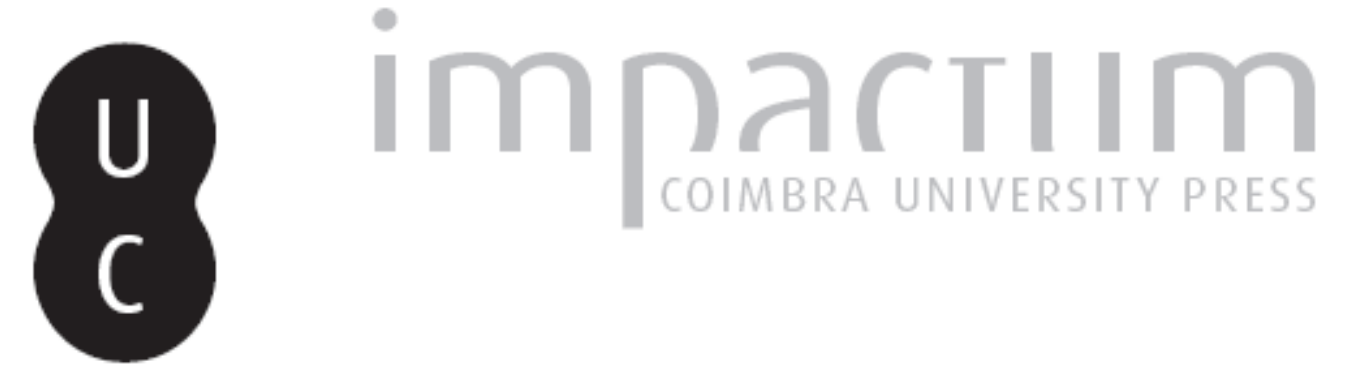

A alma italiana no coração de Lisboa: a Igreja de Nossa Senhora do Loreto

Autor(es): $\quad$ Alessandrini, Nunziatella

Publicado por: Imprensa da Universidade de Coimbra

URL persistente:

URI:http://hdl.handle.net/10316.2/42643

DOI:

DOl:https://doi.org/10.14195/0870-8584_2_9

Accessed : $\quad$ 26-Apr-2023 16:32:59

A navegação consulta e descarregamento dos títulos inseridos nas Bibliotecas Digitais UC Digitalis, UC Pombalina e UC Impactum, pressupõem a aceitação plena e sem reservas dos Termos e Condições de Uso destas Bibliotecas Digitais, disponíveis em https://digitalis.uc.pt/pt-pt/termos.

Conforme exposto nos referidos Termos e Condições de Uso, o descarregamento de títulos de acesso restrito requer uma licença válida de autorização devendo o utilizador aceder ao(s) documento(s) a partir de um endereço de IP da instituição detentora da supramencionada licença.

Ao utilizador é apenas permitido o descarregamento para uso pessoal, pelo que o emprego do(s) título(s) descarregado(s) para outro fim, designadamente comercial, carece de autorização do respetivo autor ou editor da obra.

Na medida em que todas as obras da UC Digitalis se encontram protegidas pelo Código do Direito de Autor e Direitos Conexos e demais legislação aplicável, toda a cópia, parcial ou total, deste documento, nos casos em que é legalmente admitida, deverá conter ou fazer-se acompanhar por este aviso.

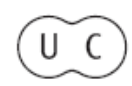




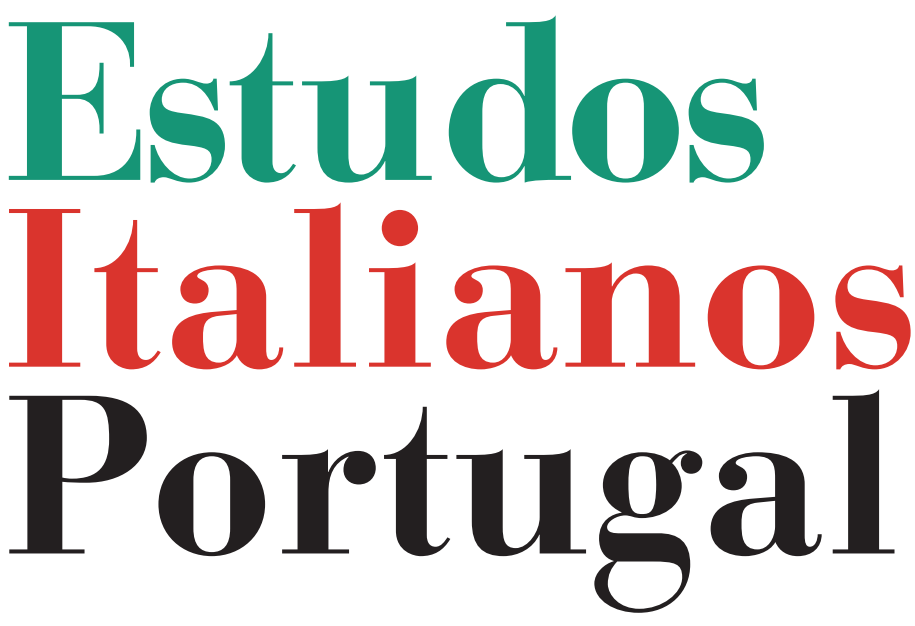

Instituto

Italiano

de Cultura

de Lisboa

Nova Série

$\mathbf{N}^{\mathbf{0}} 2$ 


\title{
A ALMA ITALIANA NO CORAÇÃO DE LISBOA: A IGREJA DE NOSSA SENHORA DO LORETO
}

\author{
NunZiatella Alessandrini ${ }^{\star}$
}

No ÂMBITO DA PESQUISA dirigida a reconstituir a actividade da comunidade italiana em Lisboa ao longo do século XVI até a primeira metade do século sucessivo, trabalhei a documentação existente no arquivo da Igreja de Nossa Senhora do Loreto em Lisboa, resolvendo utilizar parte dos documentos, na esmagadora maioria inéditos, para traçar um percurso, de modo algum exaustivo e definitivo, das linhas fundamentais que marcaram a história da Igreja do Loreto desde 1518, ano da sua construção, até 1651, ano em que a igreja sofreu um devastador incêndio que lhe causou estragos consideráveis. ${ }^{1}$

* Nunziatella Alessandrini licenciou-se em Línguas e Literaturas Estrangeiras Modernas na Facoltà di Magistero e em Língua e Literatura Portuguesa na Faculdade de Letras e Filosofia da Universidade de Bolonha. Em 2003, concluiu o Mestrado Interdisciplinar em Estudos Portugueses na Universidade Aberta de Lisboa, com uma dissertação sobre a presença italiana em Lisboa na primeira metade do século XVI. Actualmente, é doutoranda na mesma Universidade, tendo em preparação uma tese sobre a presença italiana em Lisboa no tempo da monarquia dual. Colaborou em Clio e Archivio Storico Italiano.

${ }_{1}$ Notícias históricas sobre a Igreja do Loreto: António Carvalho da Costa, Corografia Portugueza e descripçam topografica do famoso Reyno de Portugal, Lisboa, Na Oficina Real Deslandesiana, t. III, 1712; Cristovão Rodriques de Oliveira, Sumário, Lisboa, Ed. Biblion, 1938; Gustavo de Matos Sequeira, O Carmo e a Trindade-Subsídios para a história de Lisboa, Câmara Municipal de Lisboa, vol. I-II, 1939, vol. III, 1967; Norberto de Araújo, Peregrinações em Lisboa, vol. V, 1938; Júlio Castilho, Lisboa antiga-O bairro alto, Lisboa, vol. II, 1955. 
O saque de 24 de Agosto de 1580, o incêndio de 1651 e o terramoto de 1755 infligiram graves perdas ao arquivo da igreja que foi inventariado pela primeira vez em 1983 pelo Padre Sergio Filippi. No ano de 2000, os documentos avulsos das caixas que constituem parte do arquivo, foram novamente ordenados tendo sido adoptada uma metodologia diferente, desta feita por assunto. Porém, este novo trabalho de organização dos documentos não foi terminado e ainda hoje falta um inventário exaustivo e completo desta nova arrumação.

Voltando ao objecto deste contributo, recorde-se que entre a primeira e a segunda década de Quinhentos, altura em que surgiu entre os homens de negócio italianos em Lisboa a vontade de construir uma Igreja dos Italianos, existia na capital portuguesa uma sólida comunidade italiana constituída por comerciantes, mercadores-banqueiros, alguns dos quais muito abastados, homens de cultura, técnicos especializados.

Evoquemos agora muito brevemente as etapas mais significativas que marcaram ao longo de séculos o consolidar deste grupo de estrangeiros em Portugal, começando com o contrato estipulado em Fevereiro de $1317^{2}$ entre D. Dinis e o Almirante genovês Emanuele Pessagno que, obrigando-se a ter sempre 20 homens de Génova "sabedores do mar", estimulou a vinda e a permanência constante de genoveses no reino português ${ }^{3}$. A partir de então, a posição estratégica

2 Cf. João Martins da Silva, Descobrimentos Portugueses, Lisboa, Edição do Instituto para a Alta Cultura, 1944, vol. I, pp.70-71.

3 Remontam, contudo, ao século XII as primeiras notícias documentadas da presença italiana em Portugal, relacionadas com a vinda de D. Mafalda ou Matilde de Savoia, esposa do primeiro rei de Portugal D. Afonso Henriques, e do seu numeroso séquito. Sobre o assunto, cf. Luigi Cibrario, "Notizie di Matilde di Savoia, moglie d'Alfonso Henriquez, primo re di Portogallo", in Memorie della Real Accademia delle Scienze di Torino, Torino, s. II, tomo XI, 1851, pp. 287-289; Francesco Ercole, "Mafalda di Savoia prima regina di Por- 
do porto de Lisboa juntamente com os privilégios régios atraíram os comerciantes italianos na capital portuguesa em número sempre crescente. De facto, a conduta dos monarcas portugueses visava, simultaneamente, não prejudicar os naturais do reino de Portugal e salvaguardar os interesses dos vários mercadores estrangeiros.

O ocaso do século XV, com a grande aventura de Vasco da Gama, abre as portas à chegada de mercadorias valiosas, especiarias, pedras preciosas, tecidos finíssimos, porcelanas magníficas, e, contemporaneamente, à constante partida de armadas para o Oriente. ${ }^{4}$ Os mercadores italianos não se puseram à margem e os donos das já famosas companhias comerciais participaram activamente na armação de navios que, por volta de Março-Abril deixavam o porto de Lisboa rumo a Índia Oriental. Recordamos as famílias florentinas Marchionni, Sernigi, Giraldi, a família cremonesa dos Affaitati, ou Lafetá nos documentos portugueses, os genoveses Lomellini, Centurione e Spínola, apenas para citar as mais conhecidas, e à volta destas famílias uma quantidade de mercadores italianos particulares ou pagos por elas. A intensa intervenção de homens de negócio italianos na economia portuguesa era apoiada pela coroa portuguesa que precisava continuamente de dinheiro para suportar os onerosos gastos sustentados para manter o monopólio da carreira da India.

togallo", in Relazioni storiche fra l'Italia e il Portogallo. Memorie e documenti, Roma, Reale Accademia d'Italia, 1940, pp. 87-89. Documentos avulsos noticiam a presença de italianos, nomeadamente de Pistoia e de Génova, nos finais do século XIII. Trata-se de uma carta de quitação régia de 21 de Dezembro de 1347 acerca duma dívida paga pelo Concelho de Lisboa em 16 de Junho de 1296 aos mercadores da Companhia de Pistoia, e de um documento de 1278 referente à doação feita por D. Afonso III do castelo e vila da Lourinhã, onde aparece um "don Vivaldo genovês, cidadão de Lisboa”, cf. Virgínia Rau, Estudos de Histórias, Porto, Editorial Verbo, 1968, p.14.

4 Entre 1500 e 1519, partiram 234 navios da carreira da Índia com destino ao Oriente, cf. C. R. Boxer, O Império Marítimo Português 1415-1825, Lisboa, Edições 70, p. 365. 
É precisamente nesta altura que os italianos residentes em Lisboa se consciencializam da sua importância enquanto grupo, da sua força e autonomia no seio da sociedade portuguesa.

Apesar da diversidade da proveniência, da condição social, da profissão ou de distintas sensibilidades políticas, estes italianos sentiam-se ligados por um profundo sentimento religioso que foi sustento duma férrea vontade de construir e apoiar contra qualquer adversidade e por vezes à custa de consideráveis sacrifícios, uma igreja, espaço de culto e elo com a mãe-pátria, onde podiam falar a língua materna e, como resulta dos livros mestres, onde podiam tratar de assuntos relativos aos vários comércios.

Não sabemos ao certo se o lugar preexistente à dita igreja fosse um nicho ou uma ermida, visto nos documentos do arquivo aparecerem informações contraditórias acerca de tal assunto. Foi por isso e por não ter encontrado nenhuma referência, após demorada pesquisa, que Gustavo Matos Sequeira chegou a optar pela hipótese da presença dum nicho na muralha que o rei D. Fernando mandou construir no ano de 1373 para pôr a cidade ao abrigo de eventuais cercos ${ }^{5}$. Esta conjectura é suportada pela comprovação da existência em Lisboa, antes do terramoto de 1755, de vários nichos dedicados a Santo António, embora ocorram notícias escritas apenas no que se refere ao da Mouraria ${ }^{6}$.

Júlio de Castilho, contudo, defende algo de diverso, já que aponta para a presença duma antiga ermida dedicada a Santo António na parte norte ocidental da porta, sustentando ser muito frequente aparecer vestígios de capelinhas a povoarem os ermos à volta dos grandes centros ${ }^{7}$.

5 Gustavo de Matos Sequeira, op. cit., vol. I, p. 293.

${ }^{6}$ Cf. Augusto Soares de Azevedo Barbosa de Pinho Leal, Portugal Antigo e Moderno, Braga, Cota d'Armas Editores e Livreiros, 1990, vol. IV, p. 273 (edição facsimilada comemorativa do $1^{\circ}$ centenário da publicação da primeira).

7 Cf. Júlio de Castilho, op. cit., p. 13. 
Seja como for, fosse um nicho ou fosse uma ermida, o que é absolutamente certo é que os italianos residentes em Lisboa nestas primeiras décadas do século XVI, sentiram a necessidade de se reunir à volta duma igreja própria, de constituir uma confraria que dependesse directamente da Santa Sé de Roma, substituindo a devoção a Santo António pela devoção à Virgem do Loreto cujo culto, já antigo em Itália mas novo em Portugal, atingiu nesta altura uma forte intensidade ${ }^{8}$.

${ }^{8}$ Idem, p. 18. É oportuno recordar, embora muito brevemente, os elementos essenciais da tradição lauretana que desde o século XIV foi objecto de extraordinária devoção em Itália. Este facto, provavelmente, explica a escolha, por parte de "emigrantes" italianos, de dedicar uma igreja a Nossa Senhora de Loreto. A partir do século XV, a tradição lauretana começou a ser fixada em escritos específicos. Cito apenas dois textos: a Translatio miraculosa de Pietro Giorgio Tolomei, chamado Teramano, reitor do santuário de Loreto desde 1450 até 1473, indicado como o primeiro texto sobre a lenda da Santa Casa; e Virginis Mariae Loretae Historia de Giacomo Ricci, canónico da catedral de Brescia. Estes textos, principalmente o segundo, não inventam os factos mas remetem para uma tradição, provavelmente oral, já existente. Reza a lenda que o quarto da Virgem Maria em Nazareth foi transportado pelos anjos até a Ilíria onde chegou a 9 de Maio de 1291. Passados alguns anos, devido à escassa devoção das pessoas, os anjos levaram a Santa Casa supra mare no território de Recanati, na região italiana das Marche, até à selva da senhora Loreta, a 10 de Dezembro de 1294, "E in quel tempo il tempio prese il nome di Loreta, perché tutto ciò che era nella selva si diceva anche che fosse di Loreta", Giacomo Ricci, Virginis Mariae Loretae Historia (tradução do latim feita por Giuseppe Santarelli, 1987), fl. 23v. O povo, continua G. Ricci, "sbigottito dalla grandezza della cosa, vi accorreva in folla, (...) e la devozione aumentava di giorno in giorno sempre più". Devido à grande afluência de peregrinos, contudo, verificaram-se actos de violência e roubos ao ponto de os anjos transportarem a Santa Casa na colina onde actualmente se encontra, chamada Monte Prodo. A actual basílica que engloba a Santa Casa começou a ser construída em 1469 por vontade de Nicolò delle Aste, então bispo de Recanati. Supõe-se, contudo, que uma igreja de menores dimensões tivesse protegido a Santa Casa na fase anterior à construção do santuário de Loreto. O texto de Giacomo Ricci salienta a extraordinária devoção à Virgem de Loreto que se irá prolongar ao longo dos séculos XVI, XVII e grande parte do século XVIII e que se propagava além dos limites da região Marche. De facto, num inventário efectuado a 5 de Outubro de 1469, Giacomo Ricci relata a presença, além de inúmeros ex-voto, de retratos de personagens "una figura di 
Foi assim que os mercadores italianos decidiram comprar um terreno na freguesia dos Mártires e oferecê-lo à Igreja de S. Giovanni in Laterano "donatione perpetua et irrevocabili", solicitando ao Sumo Pontífice, na altura Leão X, a autorização para construírem uma igreja com protecção e privilégios derivados da sua agregação ao Capítulo Lateranense, pagando anualmente um foro "di mezza libbra di Cera Bianca lavorata"10. O contrato da compra do terreno desapareceu, provavelmente no incêndio de 1651, podendo-se, eventualmente, consultar no Arquivo do Capítulo Lateranense ${ }^{11}$.

Embora a morte ocorrida a 20 de Abril de 1518 tivesse impedido ao pontífice Leão X conceder de sua própria mão os ditos privilégios, estes foram, contudo, confirmados e conferidos pelo seu sucessor Clemente VII com uma bula de 1521 , logo seguida por outra de $1523^{12}$ com que "prese sotto la sua prottezione e dipendenza la Chiesa sud. ${ }^{\text {a }}$ costituendola per parochia di tutti l'Italiani dimoranti in Lisbona (...), ${ }^{13}$ permitindo que fosse construída “ (...) torre com sinos, semeterio, Pia Baptismal, e tudo o mais que se costuma conceder as Igrejas parochiaes" 14 .

Lorenzo Pietro di Francesco Medici, uno stemma di Filippo Borromeo di Milano", assim como a presença de tábuas em prata representantes cidades italianas, nomeadamente Cremona, Ferrara e Fermo. Cf. Giuseppe Santarelli (a cura di), Giacomo Ricci, Virginis Mariae Loretae Historia, Loreto, 1987, p. 83.

9 ANSL, Caixa I, doc. 21, Cópia da bula do papa Paulo III de 4 de Janeiro de 1539.

10 ANSL, Caixa $V$, doc. 16. A bula de 4 de Janeiro de 1539 enviada de Roma à Igreja do Loreto, sendo papa Paulo III, confirma as mencionadas modalidades “(...) sub annuo, ac perpetuo cânone, et recognitione unius mediae librae cerae albae laboratae hic Romae in manibus cameraris nostri pro tempore existentis singulis annis in vigília nativitatis sancti Joannis Baptistae solvendi (...)”, ANSL, Caixa I, doc. 21.

11 Conforme indicação presente no ANSL, Caixa I, doc. 3.

12 ANSL, Caixa I, doc. 20 .

13 ANSL, Caixa I, doc. 3.

14 ANSL, Caixa III, doc. 15. 
O terreno em que a igreja foi edificada, “ (...) he aquelle mesmo que no anno de 1502 mandou o Snor El Rey D. Manoel que a Câmara desta Cidade o forasse a Pedro Lopes seo Peloteiro, e moço da Estribeira, porque segundo se declara no emprazamento fl. 29 , estava o tal chão entre o muro da cidade e a barreira, salendo das portas de S. Catherina para aquelas do Norte, desde a primeira torre que está acerca da dita Porta, athe a segunda, que está a par das cazas, onde fazem as bombardas, em o qual há de longo ao longo o dito muro vinte, e sete braças e meia de craveira; e de largo desde o dito muro athe ao muro da Barbacam, três braças e meya de craveira esforçada" ${ }^{15}$. A primeira torre era aquela que estava diante da porta principal e que bloqueava uma desejada ampliação da igreja, facto este que levou os confrades a pedir licença ao rei D. João III para a derrubar. Embora a licença tivesse sido recusada, os italianos irão, anos mais tarde, concretizar tal pretensão.

O terreno foi vendido, como consta duma escritura de 1505, a Duarte de Azevedo e, depois da sua morte, passou ao filho Rui Dias de Azevedo que, em consequência de disputa com o Senado, foi obrigado a fechar uma porta da sua casa que dava para o muro da cidade $^{16}$.

Foi assim que, obtida licença e isenção da jurisdição do Patriarca de Lisboa e do cabido da Freguesia dos Mártires, os homens de negócio italianos procederam à edificação da sua Igreja, constituindo "A Confraria de nossa Senhora do loreto $\mathrm{E}$ a do santo sacramento $\mathrm{E}$ a da santa caterina todas três administradas per mercadores ytalianos. (...) A confraria de santo antonio administrada pollos jndios da cidade" ${ }^{17}$.

15 ANSL, Caixa III, doc. 12.

${ }^{16}$ Rui Dias de Azevedo foi obrigado a fechar a porta "Com o pretexto de que fazia má vizinhança, e servia de impedimento aos Officios Divinos, o que elle negava, allegando ser devoto de N.S. de tal sorte que cedera o dito chão para nelle se fazer a mesma Igreja", $i b$.

${ }^{17}$ Cristóvão Rodrigues de Oliveira, op. cit., p.16. 
A Igreja do Loreto foi aberta ao culto a 8 de Janeiro de 1522, sob o reinado de D. João III que permitiu o uso da antiga muralha da cidade, fora das portas de Santa Catarina ${ }^{18}$.

Os problemas à volta da edificação da Igreja da Nação Italiana eram as mais das vezes de natureza económica, já que em 1551 a capela-mor ainda não estava acabada devido à suspensão das obras por falta de verbas ${ }^{19}$. De facto, tudo indica que o quatro por cento com que os italianos se auto taxavam a favor da Igreja do Loreto parecia ser insuficiente para a continuação dos trabalhos.

Foi então que o rico comerciante florentino Luca Giraldi adquiriu simultaneamente algumas casas vizinhas que pertenciam à viúva de Rui Dias de Azevedo ${ }^{20}$ e assumiu o encargo de acabar à sua custa a capela-mor para a ornar com as armas da casa Giraldi e para ser a sepultura dele e dos seus descendentes. O contrato foi estipulado a 2 de Março de 1551 em presença do provedor, mordomo e mais confrades, e a capela, em troca de três mil cruzados, tornou-se propriedade do rico florentino ${ }^{21}$. É preciso destacar que os termos em que este contrato foi redigido, deram razões para a Mitra Patriarcal atacar, mais uma vez, a confraria do Loreto, alegando que "a ninguém he lícito por armas na igreja senão aos fundadores, ou patronos" 22 .

Ulteriores obras na igreja tornaram-se possíveis graças aos intróitos provenientes das esmolas e, principalmente, das doações deixadas pelos fiéis. As cláusulas dos legados eram praticamente sempre as mesmas, baseando-se na condição de os confrades terem a obrigação de satisfazer os legados pretendidos nas condições pretendidas.

18 Cf. João Baptista de Castro, op. cit., p. 322.

19 ANSL, Caixa IX, doc.1b.

20 ANSL, Livro do Registro das propriedades foreiras à Igreja, fl.11.

21 ANSL, Caixa IX, doc. $1 b$

22 ANSL, Caixa III, doc. 12. 
Deve-se assinalar, porém, que nem sempre o cumprimento dos legados era satisfeito devido aos custos que muitas vezes excediam as entradas. Por isso, das 26 capelas de missa apenas ficaram 9 depois de terem sido suspensas 17 por breve pontifício de 6 de Março de $1776^{23}$.

Na maioria dos casos, os donativos eram constituídos por bens imóveis, tal como terrenos cultivados, casas, ou rendas em dinheiro. Luca Giraldi, além do dinheiro pago para a propriedade da capela-mor, deixa mais uma renda de trinta cruzados por ano para o capelão rezar uma missa por dia, ao amanhecer, pela sua alma e dos seus descendentes.

O Livro Mestre da Receita e Despesa dos anos 1619 até 1651 aponta também para outro tipo de entradas, ajuda preciosa para melhorar a organização da igreja. Algumas eram de carácter geral como a venda de sepulturas ou a compra de casas pertencentes à igreja por parte de membros da comunidade italiana, outras de carácter mais pontual como, por exemplo, o envio dum fardo de anil da Índia por Nicolau Cochino $^{24}$ em 1587.

Uma primeira ampliação da igreja realizou-se com o alvará régio de 10 de Julho de $1573^{25}$ emitido pelo rei D. Sebastião que concedeu à Nação Italiana a faculdade de demolir a torre norte da Porta de Santa Catarina que estava mesmo diante da porta principal da Igreja do Loreto. Tendo a torre uma

${ }^{23}$ Destas 26 capelas de missa, 11 não tinham obrigação de coro: 3 fundadas pela Confraria; 3 por Antónia da Silva Sant'Anna; 2 por Clemente Félix; 1 por Gio Andrea Cambiaso; 1 por Paolo Giuseppe de Andrade; 1 por Clemente da Fonseca; as 15 capelas com obrigação de coro: 4 fundadas por Nicoló Micone; 8 por Franco André Carrega; 3 por Cesare Ghersi, Gio Tomaso Ghersi e Gio Mattia Ghersi. Cf. ANSL, Caixa XV, doc. 1.

${ }^{24} \mathrm{Na}$ altura, Nicolao Pietro Cochino era vedor da fazenda em Cochim. Cf. Relatório sobre o trato da pimenta, AGS, Secretarias Provinciales, Cod. 1571, in Documentação Ultramarina Portuguesa - Centro de Estudos Históricos Ultramarinos - Lisboa, 1963, vol III. Em 1593 é Provedor da Igreja do Loreto.

25 Alvará régio de 10 de Julho de 1573, in Eduardo Freire de Oliveira, Elementos para a história do município de Lisboa, vol. V, p. 348. 
função principalmente defensiva, foi imposta à confraria a condição que, por motivos de segurança e em caso de necessidade, a Confraria de Nossa Senhora do Loreto tivesse a obrigação de entulhar a igreja até a altura necessária de molde a garantir a defesa da cidade. Como se vê, a licença outrora recusada por D. João III vem a ser alcançada com o neto dele, e os confrades de Loreto obrigaram-se a cumprir esta directiva com escritura de 29 de Janeiro 1577. ${ }^{26}$

Antes de a torre ser demolida, estava prevista, numa das cláusulas da escritura, uma vistoria por parte do vereador da cidade que, a 24 de Abril de 1577, veio tratar com o provedor e irmãos da confraria sobre o modo como se devia prolongar e dar serventia à porta principal, para garantir a defesa da cidade. Neste documento noticia-se a presença de "mice felipe terzo ${ }^{27}$, arquiteto ytaliano e forteficador, e asi Benito de morales, outrosi arquiteto, e João dolva [sic] outrosi arquiteto, e asi dom $\operatorname{Ir}^{\circ}$ de Meneses", os quais unanimemente concordaram que a igreja fosse alongada "asi e da manr a como está a traça e prampta p.lo sõr vreador e arquitetos e dom $\operatorname{Ir}^{\circ}$ asinada" 28 .

Continuam as obras de melhoria da igreja com Francisco Giraldi $^{29}$, filho de Luca Giraldi ${ }^{30}$, ao qual é proposto um

26 ANSL, Caixa III, doc. 12.

27 Encontramos Filippo Terzi entre os administradores da Igreja do Loreto a partir de 1590, cf., ANSL, Livro Mestre da Receita e Despesa 1619-1651.

28 Eduardo Freire de Oliveira, op. cit., vol.V, p. 349.

29 Luca Giraldi nunca casou mas teve dois filhos, Francesco e Luísa, de uma mulher solteira, dos quais pediu carta de legitimação ao Rei D. João III. Francisco Giraldi, tal como o pai, gozava de todo o respeito da corte portuguesa: desempenhou o papel de embaixador a Inglaterra para o rei D. Sebastião e, com carta enviada em 12 de Março de 1588 ao vice-rei da Índia Duarte de Meneses, o rei de Portugal informa enviar Francesco Giraldi como Governador da Costa do Brasil. Cf. Archivo Portuguez Oriental, Imprensa Nacional, $3^{\circ}$ fascículo, 1861, p. 149.

${ }^{30} \mathrm{Na}$ Caixa XIX do ANSL encontra-se uma certidão autêntica dum reconhecimento feito em 1557 por Luca Giraldi do "senhorio direito a favor do Senado da Câmara de uma caza ao longo e dentro do muro da cidade às Portas de Santa 
acordo para abrir fendas no muro contíguo às suas casas para iluminar a igreja. $\mathrm{O}$ contrato foi estipulado com a cláusula que o proprietário as pudesse fechar em qualquer altura que achasse conveniente.

Para o enriquecimento do interior da igreja e para o acréscimo da sua fama concorreu a iniciativa do Monsenhor Accovamboni, Bispo de Fossombrone, Colector Apostólico com poderes de Núncio em Portugal desde o ano de 1614 até 1621, que, vendo o pouco ou quase nulo conhecimento que havia em Portugal dos santos italianos, nomeadamente S. Carlo Borromeo ${ }^{31}$, Arcebispo de Milão, e Santa Francisca Romana, pouco tempo antes canonizada pelo Papa Paulo $\mathrm{V}$, resolveu erigir à sua custa na Igreja dos Italianos uma sumptuosa capela dedicada aos dois santos. Era o primeiro ano da sua Colectaria. No ano seguinte fez uma soleníssima procissão em honra deles na qual participaram, segundo documento da época, mais de 800.000 pessoas, até dos reinos vizinhos " $\mathrm{E}$ foi tanta a magnificência que correo fama de que não havia memoria de outra egual em Portugal e Hespanha" 32 . Esta procissão aumentou a devoção dos fiéis a estes santos em Lisboa e tornou, assim se lê na relação, a Igreja do Loreto ainda mais frequentada, considerada a exigência de Monsenhor Accovamboni dum Breve de Roma que autorizasse uma irmandade de S. Carlo composta por italianos e portugueses nobres e plebeus e uma irmandade feminina de S. Francisca Romana.

Caterina, na Travessa que ia para a Trindade e contiguas à Igreja do Loreto, as quaes pagavam foro anual ao Senado de Lisboa 547 reis, e eram de Sebastião de Sá de Menesez, em Maio de 1652 quando esta certidão foi passada”.

31 Carlo Borromeo era sobrinho do papa Pio IV. Arcebispo de Milão desde 1565 até a morte ocorrida em 1584, tinha desempenhado o cargo de Secretário de Estado em Roma durante cinco anos ao serviço do tio. Homem rigoroso, renunciou a todos os seus bens e conduziu uma luta implacável para o reconhecimento da supremacia do poder espiritual sobre o temporal.

32 ANSL, Caixa XV, doc. 13. 
Tendo o Cardeal Borromeo de Milão tido conhecimento desta devoção dos portugueses por S. Carlo seu primo, enviou ao monsenhor Accovamboni a casula com que S. Carlo costumava celebrar a missa. Para conservar esta preciosidade e para que fosse vista pelo povo, mandou arranjar o monsenhor um lugar junto à Capela de S. Carlo para o qual se subia "por uma escada de pedra muito boa até um poial que correspondia à Egreja e servia para mostrar ao povo a Santa Casula nas principais festas do ano, a que concorria muita gente" 33 .

No que diz respeito à capela dedicada à Santa Catarina situada na Igreja do Loreto junto ao Altar-mor do lado da Epístola, sabemos que, sob o padroado do mercador florentino Júlio Nessi, foi comprada pela Confraria do Loreto, com escritura de 20 de Abril de 1618, pela quantia de trezentos mil reis e, em 1620, adquirida pela mesma quantia pelo mercador italiano Francesco della Corona, para ele e seus descendentes se sepultarem nela, com a declaração que

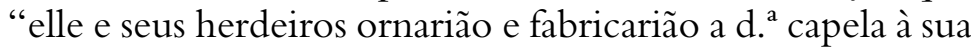
custa" 34 . De facto, cláusula imprescindível, sine qua non, para manter a posse das capelas era a obrigação de as conservar no mesmo estado ao longo dos anos, e, caso se verificasse a necessidade, prover à sua reconstrução ou às obras que fossem necessárias, caso contrário, perdia-se qualquer direito. Foi o que aconteceu à Capela-mor de Luca Giraldi. No Livro do Inventário há notícia da sentença, em 1652, proferida contra Sebastião de Sá Meneses, sucessor do comerciante florentino, neto de Francisco Giraldi, que, por ter deixado de a reedificar depois do incêndio de 1651, perdeu a posse “da capela Mor com hua casa pia e sua tribuna". Por isso, em 1658, foi necessário reunir a Junta a 29 de Abril para decidir sobre a petição de D. Maria Giraldi, filha de Francisco Giraldi e mãe de Sebastião de Sá e Menesez, que, mori-

$33 \mathrm{Ib}$.

34 ANSL, Caixa IX, doc. 4. 
bunda, mandou dizer aos confrades do Loreto que desejava ser sepultada na capela-mor ao lado dos seus antecessores.

Para ter uma ideia das posses da Igreja do Loreto até ao período que interessa para este trabalho e que se tornaram possíveis graças sobretudo às doações dos fiéis, são importantes uma série de documentos que encontrei distribuídos nas caixas XVI, XVII e XVIII. A compra de propriedades por parte da confraria enriquecia a igreja, quer do ponto de vista do aumento do próprio património, quer do ponto de vista da ampliação da estrutura do monumento. Na verdade, as casas que João Gomes tinha adquirido em 1644 a Pedro Luís Cordeiro, e que se encontravam situadas na Rua Larga de São Roque, pagando foro ao Senado de 400 reis, foram compradas pela confraria do Loreto e demolidas, servindo à construção da Sacristia na segunda reedificação depois do incêndio de 1651..$^{35}$ Também as casas situadas na Rua Direita do Loreto que os confrades compraram a Joanna d'Aguiar foram logo demolidas para edificar a Sacristia ${ }^{36}$.

Logo a seguir ao incêndio de 1651, o provedor e irmãos da confraria do Loreto "como determinavão continuar com as obras da dita Igreja e reformar a fabrica della que se lhe queimou no incêndio a qual se havia de fazer com esmolas que algumas pessoas deixarão para a dita obra" ${ }^{37}$, tendo notícia que o rei vendia os foros das propriedades que lhe eram foreiras, resolveram apresentar pedido de compra ao senado da cidade de Lisboa. De facto havia propriedades "na Rua Larga de São Roque (...) e na travessa que vay das ditas portas para a Igreja da Trindade" que pagavam, em conjunto, 6.998 reis por ano de foro à cidade. A escritura da compra foi celebrada a 16 de Maio de 1662. ${ }^{38}$

\footnotetext{
35 ANSL, Caixa XVI, doc. 11.

36 ANSL, Caixa XVI, docs. 10 e 12.

37 ANSL, Caixa XVII, doc. 4.

$38 \mathrm{Ib}$.
} 
Foi assim que ao longo de pouco mais de um século, a incansável obra dos italianos permitiu a edificação de uma igreja que "por sua formosura" era tida como uma das mais grandiosas da cidade de Lisboa.

Os trabalhosos assuntos com que a confraria do Loreto se viu inúmeras vezes confrontada relacionavam-se, na maior parte das vezes, com questões com particulares, com as instituições eclesiásticas locais, e tratavam dos casos mais variados, desde a cobrança das rendas e todas as questões ligadas às suas propriedades, até aos empréstimos de dinheiro que a Confraria frequentemente fazia e que lhe traziam muitos problemas devido à insolvência dos devedores aos quais eram consequentemente penhorados os bens. ${ }^{39} \mathrm{Um}$ trabalho delicado e dedicado, portanto, embora a confraria fosse, na sua esmagadora maioria, constituída por mercadores familiarizados com qualquer tipo de transacção e de relações públicas.

Se exceptuarmos uma dissidência ocorrida entre os membros da confraria em 1679, podemos afirmar que, pelo que emerge dos documentos do arquivo, os confrades do Loreto trabalharam juntos sem grandes divergências dentro do Compromisso dos Estatutos por que se regia a administração da Igreja. Os estatutos antigos, queimados no incêndio, foram renovados a 3 de Setembro de $1679^{40}$, depois de reedificada a segunda igreja, e voltaram a ser reformados em $1690^{41}$ e, por serem alvo de frequentes citações nos documentos espalhados nas 28 caixas, é possível reconstruir alguns dos elementos básicos da sua antiga constituição. Para o governo da igreja e a sua administração eram nomeados 13 confrades com título de votantes, "e delles três que chamam da Mensa" eleitos cada ano com o título de Provedor, Mordomo e Escrivão Tesoureiro. Os cargos dos três oficiais consistiam em cobrar as rendas, pagar os ordenados

39 Nas Caixas XX, XXI e XXII, são recolhidos, entre outros, documentos relativos a penhoras, sentenças contra devedores da igreja, intimações.

40 ANSL, Caixa $V$, doc. 7 (cópia autentica).

${ }^{41}$ ANSL, Caixa $V$, doc. 1. 
aos capelães e tratar das despesas necessárias. Além disso, tinham o dever de defender as causas da igreja, nomear os capelães e mais ministros da igreja, dando conhecimento de todos os actos assinando com os seus próprios nomes. $\mathrm{O}$ dinheiro cobrado era depositado numa caixa de ferro com três chaves distribuídas a cada um dos oficiais na altura do seu serviço.

Nos estatutos renovados de 1679 era estabelecido o número de votantes nas Juntas, bem como os deveres dos oficiais da Mesa. Doze eram os italianos que, chamados pelo provedor com bilhete compilado pelo escrivão, deviam votar, em segredo na casa do despacho, para eleger os novos oficiais e, eventualmente, conferir sobre as questões que eram apresentadas nas reuniões das Juntas. Dos oficiais da Mesa a figura proeminente era o Provedor cujo cargo incluía a faculdade de convocar a Junta sempre que achasse oportuno, mas pelo menos duas vezes por ano, no Domingo de Ramos para confirmar ou despedir o pároco, e na altura mais perto da festividade de Nossa Senhora para a eleição dos novos oficiais. Nas mãos do provedor entrava todo o dinheiro das rendas da igreja que ia ser anotado no livro da administração do escrivão. Os outros oficiais da mesa eram o mordomo, cujo cargo consistia em cuidar da cera, entregá-la para o uso ordinário e voltar a recuperá-la, e o escrivão que, além de redigir os bilhetes para as reuniões da junta, conservava o livro da administração, indicando as receitas e despesas do seu ano. Além destes oficiais, havia mais um italiano escolhido entre os votantes das Juntas que tivesse conhecimento de contabilidade ao qual era entregue o livro mestre das entradas e despesas da igreja para descobrir e corrigir eventuais erros. Além do livro mestre, os estatutos previam a presença dum livro em que todos os italianos moradores na cidades de Lisboa deviam declarar o próprio nome, apelido, proveniência e morada na cidade, para que em caso de necessidade a igreja pudesse oferecer os seus serviços.

Já adiantei que a aceitação por parte da Basílica de S. João em Latrão da Igreja do Loreto como igreja agregada, garan- 
tia que esta pudesse gozar duma série de privilégios que tal anexação previa, e, sobretudo, garantia a sua directa sujeição à Santa Sé. Este privilégio foi a causa das dificuldades que a Confraria do Loreto teve, logo a seguir à sua constituição, com o Patriarca de Lisboa e o Cabido da Freguesia dos Mártires, a que a Igreja do Loreto distritalmente pertencia. ${ }^{42}$

Neste quadro é preciso destacar a quantidade de indulgências que tinham vindo a ser concedidas pelos diversos pontífices à Basílica de S. João de Latrão "la quale ancora è Prima Capo, e Madre di tutte le Chiese di tutto il mondo"43, indulgências de que gozavam todas as igrejas anexadas.

Os privilégios pedidos e obtidos pelos confrades da Igreja do Loreto tinham a ver com a faculdade deles próprios poderem proceder à nomeação dos capelães para a administração de todos os sacramentos e, sobretudo, com a sujeição directa da igreja ao Pontífice o que significava completa liberdade face à Mitra Patriarcal de Lisboa ${ }^{44}$.

42 ANSL, Caixa III, doc. 15.

43 ANSL, Caixa I, doc. 8. Este documento contém o sumário das indulgências concedidas à basilica de S. João de Latrão, e a este propósito lê-se:"(...)se gli uomini sapessero quante sono l'Indulgenze nella chiesa di San Giovanni Laterano da molti Pontefici à essa concesse, non sarebbe bisogno di andare al Santo Sepolcro Gerosolimitano, ne meno à San Giacomo di Galizia”.

44 "Os homens de negócio Italianos (...) impetraram em o ano de 1523 do Papa Leão X, privilegio para poderem ereger a ditta Igreja (...) e que os Confrades della podessem nomear cappellão, e cappellães, que lhes administrassem os Sacramentos, desobrigassem pela obrigação da Quaresma, baptizassem seus filhos, dessem o Sant.mo Viático, e extrema unção aos seus enfermos, enterrassem os corpos dos seus defuntos onde houvessem falecido indo os buscar com cruz, procissão, e solemne pompa, assim e na forma das mais Igrejas parochianas desta cidade, e das da Romana Cúria, e que ditta Igreja se incorporasse na da Santa Sé de S. João de Laterão de Roma, e ficasse imidiatamente sojeita ao Romano Pontífice, para por este modo, e como Igreja parochial poder livre, e licitamente obrar a concessão dos sobreditos privilégios sine ulla licentia requisita.", ANSL, Caixa I, doc. 15. Na bula de Clemente VII (Caixa I, doc. 20) de 1523 há um elenco dos ditos privilégios e a sua confirmação, bem como no breve do Papa Bento XIII (Caixa I, doc. 19) de 20 de Abril de 1726. 
Com o aumentar do número de fiéis, aumentaram também as ofertas, e a Paróquia dos Mártires começou a alegar direitos sobre as esmolas. A situação agravou-se quando os confrades italianos decidiram tornar a Igreja do Loreto numa paróquia isenta. Em 1545, o Cabido Metropolitano de Lisboa apresentou queixa ao Papa Paulo III que enviou a causa para o Tribunal da Sacra Rota. A sentença verteu a favor do Cabido de Lisboa, dispondo a anulação da bula de 1518 e da sua confirmação de 1523, alegando que os confrades italianos não podiam instituir paróquia no distrito da freguesia de Nossa Senhora dos Mártires sem o consentimento do cabido da cidade, sendo condenados a pagar 482 cruzados e obrigados a não utilizar os direitos paroquiais. De igual modo foi vincado que os privilégios concedidos pelo Capítulo Lateranense teriam sido válidos apenas no que dizia respeito às graças espirituais.

A 6 de Setembro de 1550 foi celebrada uma escritura de convenção, confirmada a 22 de Janeiro de 1551, entre a confraria do Loreto e o Cabido de Lisboa Oriental em que os confrades italianos renunciavam aos seus privilégios. Foi estabelecida a nova paróquia e o Patriarca, a 24 de Janeiro do mesmo ano, mandou fazer a delimitação da Paróquia de Nossa Senhora do Loreto e absolveu a confraria do pagamento dos 482 cruzados. Os limites foram bem traçados para que não houvesse interferências com a Paróquia dos Mártires da qual foi assim separada ${ }^{45}$ e, se seguirmos a distribuição

45 O território da Paróquia do Loreto ia "desde as casas de António da Silveira que estam sobre o muro e porta de Santa Catarina que ficam com a ditta egreja de N.S. do Loreto, ao longo do muro, da banda de fora, até as casas e torre do Conde de Vimioso que outrossi ficam com N.S. do Loreto, inclusive. E das casas de Francisco de Frois, escrivão da Casa da Índia pela rua abaixo à mão direita e da mão esquerda com todas as casas que tem serventia para a dita rua até contestar com as casas da mulher que foi do doutor Álvaro Esteves que ficam com a igreja de N.S. dos Mártires. E dahi pela travessa que vai entre as casas de Bernardim de Távora e Frac. ${ }^{\circ}$ Carneira atee a baroca do pé das Chagas 
que Fr. Nicolau de Oliveira ${ }^{46}$ faz, em 1620, das quarenta freguesias de Lisboa pelos sete montes e vale da Baixa, podemos pensar a freguesia do Loreto estendida entre o quinto monte que "he o de Sao Roque" 47 e o sexto monte "chamado das chagas por huma Igreja, que nelle edificárão os mareantes da carreira da Índia" 48 .

A revogação dos privilégios lateranenses foi confirmada, em Junho de 1562, pelo Papa Pio IV na sua Regimini Universalis Ecclesiae ${ }^{49}$.

Sucessivamente, a bula do Papa Sisto V de 15 de Janeiro de 1586 , no primeiro ano do seu pontificado, revalida os

e todas as casas de F.co Carneiro por detraz, e por diante ficam com N.S. dos Mártires. E dahi digo e as casas que setam à barroca das chagas do amo do Conde do Vimioso por nome...ficão outrossi com N.S. do Loreto. E dahi vindo ao terreiro de António Vaz piloto da Mina ficam com N.S. do Loreto, cortando pela rua abaixo aa mão direita com as casas da mão (direita) digo esquerda que tem serventia para a ditta rua, com as casas de Marco Pires inclusive em que entra toda a povoaçam do vale de Pedro Domingues, e cortando direito ao Monte que estaa defronte e do dito monte direito ao canto das casas de Ruy Frz, as quaes casas de ruy Fernandes ficam com N.S dos Mártires, e do canto

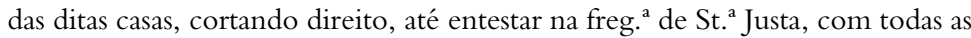
casas e quintaes que fazem dentro em este limite. E bem assim disserão mais os ditos senhores Limitadores que davão mais de limite aa dita freguezia de Nossa Senhora do Loretto ao longo do muro athe entestar com Sam Roque, e na freg. a de St. ${ }^{a}$ Justa, e com esta declaração q a todo o tempo q o Cabido na freguezia dos Martyres quiser fazer outra freguezia ou freguezias, ou na desta freguezia do Loreto que ora lhe limitam, possa tomar todas as casas e lemite assim deste que era aa ditta igreja do Loreto, tem dado como de Martyres, sem a ditta igreja do Loreto nem seos mordomos, confrades e freguezes se poderem chamar à posse", Gustavo de Matos Sequeira, op. cit., vol. I, pp. 297-298.

46 Sobre a descrição dos montes feita por Fr. Nicolau de Oliveira ver o comentário de Augusto Vieira da Silva, "As sete colinas de Lisboa", in Dispersos, Câmara Municipal de Lisboa, 1960, pp. 181-192.

47 Frei Nicolau de Oliveira, Livro das Grandezas de Lisboa, Lisboa, Na Impressão Régia, 1804, p. 118.

$48 \mathrm{Ib}, \mathrm{p} .119$.

49 ANSL, Caixa III, doc. 12. 
privilégios lateranenses, embora ficasse expressamente clara a sujeição das igrejas agregadas à jurisdição dos Bispos.

A 30 de Junho de 1593 uma sentença do cardeal arquiduque, regente do reino, determinava que a Irmandade da Misericórdia mantivesse o antigo privilégio de ter as suas próprias tumbas para os enterramentos dos irmãos e dos pobres, e de efectuar o acompanhamento destes enterros com as suas bandeiras e insígnias. Este privilégio, lê-se na sentença, era proibido a quaisquer outras confrarias ${ }^{50}$, excluindo as confrarias de Nossa Senhora do Loreto e de S. Bartolomeu de S. Gião dos Alemães, por serem freguesias particulares regidas por bulas apostólicas ${ }^{51}$.

Logo a seguir ao incêndio de 1651, mal começaram os italianos a reconstrução da igreja, recomeçaram logo os contrastes com o Patriarca que não permitia a sua isenção ${ }^{52}$. Alegando tratar-se duma nova igreja, sendo a velha destruída pelo fogo, pediam os italianos a ineficácia do contrato de 1551 que foi declarado nulo pela Nunciatura com sentença de 23 de Novembro de $1672^{53}$, comunicando que o con-

${ }^{50}$ Escreve, confirmando, em 1620, Frei Nicolao de Oliveira, op. cit., p.202: “(...) e não pode auer outra por hum Breve do Summo Pontífice, saluo a do Sanctissimo Sacramento da freguesia de Nossa Senhora do Loreto, em que se podem enterrar os seus fregueses, e a de huma, ou duas confrarias mais por particular breue de sua Santidade".

51 Cf. Vítor Ribeiro, op. cit., pp. 5-6. A sentença é reproduzida por extenso nas páginas 53-56. "E porem as confrarias de N.S. do Loreto dos Italianos e de S. Bertholameu de S.Gião dos Alemaens que chamão Estrelins são freguezias suas particulares erigidas por Bullas Ponteficias", ANSL, Caixa III, doc.12.

52 As referências aos contrastes com a Mitra Patriarcal são frequentes nas reuniões das Juntas. Cito, como exemplo, a reunião de 23 de Maio de 1666 onde se lê: "(...)havendo fatto il proveditore un breve discorso sopra essersi dilatato più per 3 anni il far gionta, et elleggere ufficiali nuovi ogn'anno, com'era

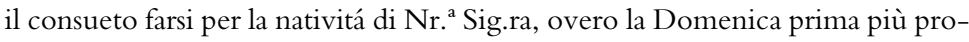
pinqua detta festa, et havendo esposte le cause di ciò, che sono le molte liti della detta Chiesa che si vano sollecitando, et in particolare quella con li Canonici di questa Metropoli,(...)", ANSL, Livro das Juntas, fl. 32.

53 ANSL, Caixa I, doc. 3. 
trato de transacção feito com o Cabido de Lisboa Oriental no ano de 1551 ficava extinto com o incêndio; a nova igreja era diversa da primeira, e portanto não obrigada ao mesmo contrato. Esta sentença foi confirmada por outra confirmativa de 29 de Abril de $1673^{54}$.

De facto, folheando as páginas do Livro das Sessões das Juntas, repara-se com o minucioso trabalho de averiguação de documentos levado avante pelos confrades no intuito de alcançar a invalidade do acordo de 1551. Ressalta destas sessões que os italianos tinham enviado à Universidade de Coimbra um quadro da sua situação e, na junta de 4 de Janeiro de 1663, os confrades do Loreto apresentam a resposta que a Universidade de Coimbra lhes tinha enviado sobre a citada pretensão do direito de jus padroado sobre a igreja reedificada ex-novo. O papel, assinado pelo Doutor Carlo Antonio Paggi, fundamentava os direitos dos italianos com as disposições do Concílio Tridentino no sentido em que " (...) todos que dotarem e fundarem e fabricarem Igrejas compete não por privileggio mas de jure, o jus padroado da dita Igreja e consequentemente apresentar livremente o Cura delle e fazer os mais actos concedidos aos Padroeiros".

Estes confrontos com a Mitra Patriarcal constam num volumoso documento ${ }^{55}$ que repercorre toda a história da igreja desde a sua fundação, sendo que o Capítulo Metropolitano encontra logo no pressuposto inicial o motivo sobre o qual fundar a sua oposição à isenção e privilégios da Igreja do Loreto. $\mathrm{O}$ alicerce desta argumentação residia no facto de a Basílica de S. João em Latrão poder anexar igrejas, e conceder-lhes privilégios, apenas quando estas estivessem construídas em solo lateranense. Ora, segundo o parecer da Mitra, este não era caso que se pudesse aplicar à Igreja do Loreto porque, apesar de os italianos terem comprado o

54 ANSL, Caixa III, doc. 16: cópia dos actos e sentenças em se avaliou a invalidez do contrato de 1551.

55 ANSL, Caixa III, doc. 12. 
terreno e terem-no oferecido à basílica romana, este não estava em seu domínio antes da edificação da igreja, estando sujeito à jurisdição ordinária. Portanto, a condição sine qua non para ser válida a união das igrejas com a Basílica de S. João em Latrão, era serem estas fundadas em solo que, antes da fundação, fosse próprio dos domínios da basílica romana.

O chão adquirido pelos italianos, prossegue a Mitra na sua fundamentação, pagava foro à Câmara em 1530 quando D. João III acordou a isenção do pagamento, e também em 1573, quando D. Sebastião concedeu o lugar onde estava a torre que foi sucessivamente derrubada. Esta verdade trazia como consequência a ineficácia das bulas de 1518 e de 1523 com a conclusão de que os italianos não podiam oferecer à Basílica de $\mathrm{S}$. João em Latrão um terreno que ainda não tinham, tendo-o adquirido nas datas acima referidas quando os monarcas portugueses lhes conferiram os ditos beneficios. E, ainda, supondo que os italianos tivessem feito a doação duma pequena parte de terreno, como podia o capítulo lateranense ser dono de todo o chão comprado depois de serem emitidas as bulas de Leão X e Clemente VII?

Mais elementos foram apresentados pela Mitra Patriarcal para justificar o seu direito. O primeiro era, como já adiantámos, a falta do "instrumento", ou seja, do contrato que provasse a validade da doação; o segundo elemento tinha a ver com uma ordenação régia, em vigor desde o reinado de D. Dinis, segundo a qual não era permitido que as igrejas do Reino de Portugal possuíssem bens de raiz sem uma licença régia ${ }^{56}$. Para

56 "De muito longo tempo foi ordenado pellos Reys nossos antecessores que nenhuas Igrejas, nem ordens podessem comprar nem haver em pagamento de suas dividas bens alguns de raiz, nem por outro titulo algum os acquirir, nem possuir, sem especial Licença dos ditos Reys, e acquirindosse contra a dita defeza, os ditos bens se perdessem para a Coroa, a qual lei sempre athegora se uzou, practicou, e guardou em estes nossos Reynos, sem contradicção das Igrejas e ordens, e nos assim mandamos que se guarde e cumpra daqui em diante.", ANSL, Caixa III, doc. 12. 
além do mais, não foi apenas o terreno que a cidade de Lisboa deu a esta comunidade estrangeira, como a ajudou com os materiais que, com toda a certeza, acrescenta a Mitra, foram tirados da demolição da torre. Finalmente, a bula de Pio IV de 1562 que derrogava o privilégio que tinha a Igreja de S. João em Latrão de agregar igrejas já fundadas. Nesta base a Mitra resolveu questionar sobre a já mencionada sentença de 1593 proferida a favor da Irmandade da Misericórdia alegando que era "bem notório que os Alemaens não tem outra freguesia senão a em que cada hum mora; também é falso que a Igreja de N.S. do Loreto he freguesia dos Italianos, porque nem ainda pelos chamados privilégios se lhes dá faculdade de constituir Parochia" ${ }^{57}$. Foi também proclamada inválida a sentença de Novembro de 1672, sendo declarado que os privilégios a que a confraria do Loreto renunciou só existiam "por chymera", tendo-se provado que nunca tinham tido efeito por não ser fundada a igreja em solo lateranense, uma controvérsia que se iria prolongar durante todo o século XVIII. 